\title{
Radiation-Related Treatment Effects across the Age Spectrum: Differences and Similarities or What The Old and Young Can Learn From Each Other
}

\author{
Matthew J. Krasin, MD ${ }^{1}$, Louis S. Constine, MD ${ }^{2}$, Debra Friedman, MD ${ }^{3}$, and Lawrence B. \\ Marks, MD ${ }^{4}$ \\ 'Division of Radiation Oncology, Department of Radiological Sciences, St. Jude Children's \\ Research Hospital, Memphis, TN \\ ${ }^{2}$ Departments of Radiation Oncology and Pediatrics, University of Rochester Medical Center, \\ Rochester, NY \\ ${ }^{3}$ Division of Cancer Control and Prevention, Vanderbilt-Ingram Cancer Center, Nashville, TN \\ ${ }^{4}$ University of North Carolina, Chapel Hill, NC
}

\begin{abstract}
Radiation related effects in children and adults limit the delivery of effective radiation doses and result in long-term morbidity affecting function and quality of life. Improvements in our understanding of the etiology and biology of these effects, including the influence of clinical variables, dosimetric factors, and the underlying biologic processes has made treatment safer and more efficacious. However, the approach to studying and understanding these effects differs between children and adults. By using the pulmonary and skeletal organ systems as examples, comparisons are made across the age spectrum for radiation related effects including pneumonitis, pulmonary fibrosis, osteonecrosis and fracture. Methods for dosimetric analysis, incorporation of imaging and biology as well a length of follow-up are compared, contrasted and discussed for both organ systems in children and adults. Better understanding of each age specific approach and how it differs may improve our ability to study late effects of radiation across the ages
\end{abstract}

\section{INTRODUCTION}

Radiation therapy (RT)-induced acute and late normal tissue effects limit the delivery of safe, therapeutically-optimal RT doses for a variety of pediatric and adult cancers. Our incomplete understanding of how to limit these normal tissue effects, while still controlling the cancer, is a major clinical problem. For example, in adults, we are often unable to deliver sterilizing doses of RT for cancers of the lung and prostate. In children, we accept that there are long-term chronic treatment effects from RT. While we know that RT is an effective anti-cancer agent, the current paradigm is one of 'radiation avoidance' in treatment and clinical trial design. Modern RT planning and delivery tools (e.g. conformal and intensity modulated radiation

\footnotetext{
(c) 2009 Elsevier Inc. All rights reserved.

Corresponding author: Matthew J. Krasin, M.D. St. Jude Children's Research Hospital, 262 Danny Thomas Place, Mail Stop 220, Memphis, TN 38105-3678, phone: (901) 595-3226, fax: (901) 595-3113, matthew.krasin@ stjude.org.

Publisher's Disclaimer: This is a PDF file of an unedited manuscript that has been accepted for publication. As a service to our customers we are providing this early version of the manuscript. The manuscript will undergo copyediting, typesetting, and review of the resulting proof before it is published in its final citable form. Please note that during the production process errors may be discovered which could affect the content, and all legal disclaimers that apply to the journal pertain.
} 
therapy) increase our ability to study and understand the dose/volume dependence of RTinduced normal tissue effects. We herein discuss some of the common normal tissue effects in adults and children, highlighting some of the differences and similarities in how these issues are addressed across the age spectrum. Differences in the timing to occurrence and the severity of RT-related treatment effects between childhood and adult cancer patients influence both the strategies for RT (including both technique and dose), and how the effects of RT are studied across the age spectrum. Understanding these differences, why they exist, and what can be derived from each approach, will foster further progress in improving late normal-tissue outcomes for our patients.

\section{General differences in RT delivery and treatment effects between children and adults}

All organ systems have specific responses to RT, and their propensity to RT-induced injury is variously similar or different across the age spectrum. Several general issues, unrelated to the nuances and characteristics of individual normal tissues, exist across these groups.

Fraction size in the era of intensity modulated radiation therapy-RT delivered to both children and adults typically uses multiple treatment fields to create a conformal dose distribution around the tumor volume. The adjacent normal tissues are usually exposed to fraction sizes lower than those delivered to the target tissues (e.g. $<1.8$ Gy per day), based on the number of beams. Across all age groups, fraction size has historically been a strong predictor of late effects when total dose for that normal tissue is held constant. Thus, this lower dose per fraction tends to lessen late effects in surrounding normal tissues. However, since the total doses in adults are often higher than in children (e.g. $\approx 70$ Gy for adult thoracic or head and neck sites vs. $45-55.8$ Gy for many pediatric diseases), this sparing of surrounding tissues may be less marked. Conversely, some late effects in children tend to occur at lower doses (e.g. growth disturbance) and are less well spared with lower fraction sizes (e.g. cancer induction).

Classification of Endpoints for Late Effects-Events are classified differently in children and adults. In adults, effects are often considered binary (e.g. present or absent) and it is common to consider a relatively short time interval for evaluation of late effects (e.g. 6-12 months for pneumonitis, 3-5 years for fibrosis or rectal bleeding). Conversely, in children where growth and development still occurs at the time of therapy and after, evaluation of late effects over long periods is considered. Since late effects are appreciated more as they evolve over time, it is more common to grade the severity (rather than the yes/no occurrence) of the events in children. Thus, this dimension of time also increases the challenge in the study of late effects. Since it may take years to decades for late effects to manifest in children, detailed follow-up is critical to assess their severity. Though it is assumed that normal tissue effects in adult patients remain stable beyond the typical five years of follow-up, studies of potentially longer-term changes are typically not available.

Patient age and vulnerability-The patient's age at the time of RT is critical in children. In general, younger children are more at risk for late effects than older children. Neurocognitive effects, development of muscles, and growth of bones all are very sensitive to the age at treatment. Each of these tissues has an age range for development and growth, with some interpatient variation. Though age can be integrated into the study and modeling of the effects of RT, the addition age as a variable further divides this already-small population into subgroups that lack power for statistical analysis. In contrast, this effect of age is less of an issue in adults because tissue response does not change as much as a function of age, despite the large spectrum of patient ages studied.

Statistical feasibility-The population size for the investigation of late effects in adults and children are different. Late effect studies in adults often benefit from large sample sizes due to 
the large number of available irradiated adults. Indeed, the relatively low incidence of severe radiation-related effects in adults necessitates large data sets to establish causative factors. For pediatric patients this situation is reversed; the incidence of malignancies requiring RT for cure is lower, yet the frequency in which measurable late effects occurs is higher. This relatively high event rate makes it possible to correlate these effects with treatment parameters and other clinical variables, despite limited numbers, yielding meaningful analyses. Table 1 summarizes the general differences in the occurrence and study of late effects between children and adults.

\section{SPECIFIC EXAMPLES OF LATE EFFECTS}

\section{Pulmonary effects of radiation therapy}

RT-related lung effects, including pneumonitis (RP) and fibrosis (RF), are a major doselimiting factor for thoracic RT in both adults and children. In adults and children, predisposing factors may effect the risk of pneumonitis and fibrosis (e.g. smoking and related chronic emphysema, pneumonia, asthma) $(1,2,3)$. These predisposing factors and the context of RT (e.g. conformal lung RT, total body RT) all interact to increase or decrease the subsequent risk of RP. Table 2 demonstrates general differences between children and adults in the development and study of RT-induced lung injury.

Clinical scenarios necessitating radiation adjacent to or in the lung-The context in which the lung receives RT differs between adults and kids. The majority of adults receiving thoracic RT have lung cancer, while the remainder have cancer in adjacent organs (e.g. mediastinal lymph nodes, breast, esophagus). Radiation doses are usually non-uniform and risks are often evaluated via dose volume histograms. Children often receive RT to the lung primarily in the context of whole lung RT (e.g. metastatic Wilm's or Ewings) where dose volume histograms are less useful. The lung is less-often exposed as an adjacent normal tissue (e.g. mediastinal radiation), though certainly this occurs in the setting of Hodgkin lymphoma and sarcoma.

Risk and predictors of radiation pneumonitis-Dosimetric factors are the mainstay of analysis for RP. An array of dosimetric parameters including mean lung dose (MLD) and volume of lung receiving dose above a certain threshold (e.g. $\left.V_{20 G y}\right)$ are most commonly used to predict RP risk in children and adults. Despite extensive analyses, no one parameter is uniformly predictive across the multiple patient datasets and disease sites and age groups (4). In adults the incidence of RP ranges widely; from $\approx 3 \%$ in adults managed with combined modality therapy (CMT) for Hodgkin's disease, to $\approx 5 \%$ in patients receiving radiation for breast cancer, to $\approx 15-44 \%$ in some patients irradiated for lung cancer (5-9). In children, the overall rate of RP for most diseases near the chest remains at the lower end of this spectrum (10-11). Available data suggests that less that $5 \%$ of patients with sarcoma adjacent to the lung and less than $10 \%$ of patients with Hodgkin's disease receiving CMT will experience clinical RP.

Diagnosis of radiation pneumonitis-There are differences in the certainty of the diagnosis for RT-associated lung injury. In adults, the symptom-based diagnosis of RP often appears in the context of confounding medical problems. Approximately $28 \%$ of adult cases of RP occur with concurrent illness (e.g. cardiac arrhythmia, COPD, pulmonary embolism), making the diagnosis somewhat uncertain (2). In contrast, children rarely have concurrent chronic pulmonary problems. Occasionally, acute pneumonia may complicate the diagnosis/ treatment of RP in children, but its response to antibiotics versus steroids usually helps clarify the diagnosis. 
Studies of predictive models for lung injury-The definition of high-risk dosimetric parameters has been the primary method for stratifying RP risk in adult patients with lung cancer, derived from large, well-analyzed dosimetric datasets. MLD, volume of lung >20-30 Gy, and normal tissue complication probability (TCP) models, all correlate with rates of RP $(4,7-9)$. These parameters still lack high predictive value, as $46-71 \%$ of patients with "high risk" dosimetric parameters do not experience RP, and 7-16\% of "low-moderate risk" patients do experience clinically-significant RP $(7,9)$. In children and young adults, there have been fewer attempts to correlate dosimetric parameters and RP risk. When dosimetric and clinical outcome data are available, the overall risk of RP is low at approximately $6 \%$, and rarely >grade 2 in patients receiving non-total body irradiation $(10,11)$. Adult models such as $\mathrm{V}_{20 \mathrm{~Gy}} \geq 35 \%$ or MLD > 16 Gy select patients at higher risk for grade 2 pneumonitis in this pediatric cohort of sarcoma and Hodgkin's disease patients, but the overall incidence is low and the nonspecificity of these models mimics the experience seen in the adult population $(4,7-9,11,12)$. Even the application of more complex TCP models to the pediatric RP population did not improve predictability $(10,11)$. When using MLD as a single dosimetric parameter one can see the similar broad range of risk predicted for adults and children (data from St. Jude Children's Research Hospital \{SJCRH\} and adult centers - Fig. 1) (13, Personal communication M.

Krasin 2009). This is not to suggest that dosimetric analysis of RP is fruitless; to the contrary these analyses suggest that dosimetric approaches are important, but are not ideal predictors alone.

Incorporating clinical, laboratory, and functional parameters into models may improve the predictive abilities of current dosimetry-only models. In adults receiving total body radiation, lung dose is the major factor predictive for RP. Assessing for concurrent cytomegalovirus infection enhances the predictions based on dose alone. (14). In non-smokers age $>59$ years receiving RT for breast cancer, the risk of RP was elevated (15). Active smoking has been implicated by others to provide a slight protective benefit, possibly related to immune suppression (1). In 606 patients with breast and esophageal carcinoma, the incidence of RP for smokers compared to non-smokers was $0.4 \%$ vs. $3.6 \%(\mathrm{p}=0.022)(16)$. These clinical findings suggest a role for inflammatory cascades in the initiation and development of RP for adult patients.

Based on the role of inflammation in the pathogenesis of RP, serum cytokine levels of TGFbeta, IL-1, and IL- 6 have been implicated as both predictors and possible mediators for development of pneumonitis and subsequent fibrosis (17-19). It is hoped that these biomarkers may enhance predictability and elucidate some of the underlying biology. However, their ability to add refinement to dosimetric variables is not universally validated $(15,17,20)$. Incorporating functional-based parameters (e.g. perfusion weighted lung dose and diffusion capacity) into predictive models may slightly improve their predictive ability for RP over single parameter dosimetric models alone (21). Functional information from early post-radiation FDG-PET imaging combined with MLD also correlated with varying grades of RP (some clinically symptomatic and some only radiographic) though identification after delivery of radiation was complete reduces its value for prediction (22). Integration of spatial information, describing dose to the geometrically defined upper and lower lung, improved upon traditional DVH-based parameters in predicting grade $\geq 3 \mathrm{RP}$ (23).

In contrast, attempts to integrate factors beyond typical conformal dosimetry in pediatric patients are more limited. Covariates such as chemotherapy have been analyzed in the context of patients receiving RT for Hodgkin's disease. When pre-radiation bleomycin was added as a covariate to V24Gy in 99 patients analyzed for risk subsequent RP (any symptomatic grade), the ability to predict risk was significantly increased (Fig. 2), though the absolute risk remained low (10, Personal communication M. Krasin 2009). 
Risk and predictors of radiation fibrosis- $R F$ is a long-term, often permanent, toxicity of RT. Despite the extensive analyses of RP in the adult lung cancer population, modern analyses of dosimetric parameters relative to RF are less common, likely due to the poor survivorship of the lung cancer population (24). In contrast, patient studies of breast cancer, Hodgkin's disease, and particularly pediatric cancer have focused on RF. The surrogates for radiation fibrosis are either clinical symptoms or findings on pulmonary function testing (PFT).

Long-term outcome data from the Childhood Cancer Survivor Study (CCSS) demonstrates that children receiving chest RT (including mediastinal, whole lung, and total body irradiation) had a significantly increased rate of reporting lung fibrosis, chronic cough, dyspnea on exertion, pleurisy, and the need for supplemental oxygen 5 years or more after diagnosis. The cumulative incidence of lung fibrosis continued to increase out to $>5 \%$ at 25 years. Similar findings were noted for chronic cough ( $>10 \%$ at 25 years), pleurisy ( $>6 \%$ at 25 years) and dyspnea on exertion (>15\% at 25 years) (25). This symptom-specific study, while not addressing the pathobiology or mechanism for late pulmonary effects in children, does highlight the specific issues faced by long-term survivors and how these issues affect quality of life on a daily basis. Interestingly, reported lung fibrosis and pleurisy was more common in patients diagnosed at age $>15$ years compared to patients age $\leq 5$ years, counter to what one would expect based on age of development of the lung and growth of the chest wall; RT dose/volume details are not reported in these subgroups. In comparison to this experience, limited data are available on long-term clinical outcomes relating to RF in adults.

Pulmonary function as measured by PFTs has been the most frequently utilized assessment tool in evaluating long-term lung injury, essentially assessing the degree of RF. Analysis of PFTs in children following mediastinal RT indicates a pattern of reduction in FEV1 and DLCO compared to non-RT controls (26). In this same study, residual volume was also reduced, possibly a restrictive deficit related to loss of compliance in an irradiated chest wall. Children receiving whole lung RT have a similar restrictive pattern with reductions in FEV1/FVC ratios and total lung capacity (27). Young age was not correlated to the severity of the deficits seen. Adult studies almost universally report a drop in normalized PFT values (forced expiratory volume in one second (FEV1), forced vital capacity (FVC) and diffusion capacity for carbon monoxide $(\mathrm{DLCO})) \approx 3$ months post-RT $(6,28)$. Some authors report a partial recovery of lung injury between 3-18 months, representing some compensatory mechanism of remaining functional lung or recovery from early damage $(6,29)$. Others, notably in patients treated for lung cancer, found no stabilization and rather continued decline in these parameters. PFT declines over time are shown in figure $3(6,28,30)$.

Imaging may serve as a surrogate metric for fibrosis. Only adult studies have assessed changes in regional perfusion following thoracic RT. Loss of SPECT-defined perfusion evolves during the first 3-12 months post-RT, and stabilizes thereafter. CT defined density changes in the lung also progress over time relative to dose (31). However, there is no clear association between these perfusion abnormalities and changes in patient's symptoms or PFTs $(32,33)$.

$\mathrm{RF}$ and late pulmonary effects remain a complex constellation of late effects incorporating alterations involving the pulmonary parenchyma, associated changes in spirometry, chest wall dysfunction, and respiratory symptoms. For pediatric patients, integration of dosimetry, functional imaging and detailed study of chest wall dysfunction is needed. Participation by radiation oncologists in the design of long-term studies incorporating baseline measurements would increase understanding. Adults stand to benefit by incorporating the long-term followup approach developed in the CCSS. Understanding how quality of life is affected beyond 5 years could support or alter RT treatment strategies currently in use. Newer trials have already begun to remedy some of these deficiencies, incorporating conformal radiation dosimetry, toxicity monitoring and detailed follow-up (34). 


\section{Skeletal effects of radiation therapy}

Bone, in contrast to lung, is less frequently considered as a dose limiting normal tissue, particularly in adults. In children, this concern is reversed; bone and its potential growth drive heated discussions at tumor boards and require lengthy consent consultations with families. The spectrum of toxicities also differs across the age range and includes fracture, osteoradionecrosis, and growth retardation (table 3).

Clinical scenarios necessitating radiation to the bone-Most RT treatment fields in both children and adults include incidental irradiation of bone. There are several regions of treatment for which special consideration is given to bone. The mandible for adult patients is considered vulnerable due to its limited blood supply, essential function, and risk from RT doses as high as 70 Gy delivered in its proximity. Weight bearing bones also deserve particular consideration as necrosis or fracture could be debilitating. Alterations in growth are a concern in younger pediatric patients where RT is delivered to growing bone. Despite the diversity of sites and toxicities, the mechanisms of bone growth, maintenance, and injury share common features across the skeletal system in adults and children.

Osteoradionecrosis-Osteoradionecrosis (ORN) of the mandible, initially described in 1920 , remains a consideration in adults receiving high dose RT (35). ORN is also seen in the maxilla and described in the sacrum $(36,37)$. The cumulative incidence of mandibular ORN in adults with head and neck cancer ranges from 3 - 8\% (38-40). ORN often occurs within two years of RT, particularly in the head and neck region when RT is delivered prior to or absent surgery $(39,40)$. When RT is delivered following surgery, or in the sacral region, ORN may occur years later $(38,39)$. Its etiology, initially thought to be of relation to vascular insufficiency, is evolving to include the formation of fibrosis and atrophy. Osteonecrosis of the mandible and maxilla in patients receiving bisphosphonates suggest that inhibition of osteoclast activity also plays a role in ORN $(41,42)$. Clinical factors associated with its formation include dental extractions, mandibular surgery, trauma to the mucosa, and higher effective radiation dose $(36,39,40)$. In the modern era, application of IMRT and other conformal techniques have reduced the incidence of ORN ( 1 in 73 "at risk" patients), felt to be primarily related to reductions in mandibular volume receiving high dose RT (43). Though a reduction in incidence may be achieved through application of modern techniques, management options for ORN are limited. Hyperbaric oxygen, thought to improve oxygenation in poorly vascularized tissue, was not found to be beneficial in a randomized controlled trial of patients with ORN (44). Conservative clinical management incorporating antibiotics and subsequent surgery remains the mainstay of treatment for ORN, though only about one-third of patients with mandibular involvement have complete healing $(36,37)$. Though a significant and long standing body of work regarding ORN exists for adults, little data is available regarding children. Prophylaxis with hyperbaric oxygen is standard when dental extractions are needed following high dose ( $60 \mathrm{~Gy})$ mandibular RT. Data to support or refute this approach is lacking and studies defining the incidence and prognostic factors of ORN in children are not available.

Fracture-RT-associated fractures are a risk for both adults and children (Fig. 4). The cumulative incidence varies based on the population studied, ranging from $<10 \%$ to $>23 \%$ in children $(45,46)$. In an institutional series of pediatric patients receiving RT for rhabdomyosarcoma, non-rhabdomyosarcoma soft-tissue sarcomas, and Ewing's sarcoma, the overall 4 year cumulative incidence of fracture was 10\% (Fig. 5) and was elevated to $29 \%$ in weight bearing bones (Personal communication M. Krasin 2009). A similar $31 \%$ rate of fracture was reported in a series of patients with Ewing's sarcoma undergoing RT to weight bearing bones (45). Fractionation also influenced risk in this study. Estimates for fracture in adults following RT also vary, but range from $4 \%$ to $29 \%$ in those with periosteal excision in addition 
to RT. Reported etiologies include prior occurrence of ORN, RT to a weight bearing bone, and additional trauma or surgery $(47,48)$. Factors such as periosteal excision or stripping increase the rate of subsequent fracture (??by) $29 \%(49,50)$. Dosimetrically, mean dose and maximum dose to 2cc of bone and V40Gy for bone all predict patients at higher risk for fracture; however, the absolute magnitude of the increased risk in patients with unfavorable dosimetric parameters is a modest $10 \%$, thus a RR 1.1. This suggests that such dosimetric factors are sub-optimal predictors of a truly high risk group (51). Though not frequently discussed as a normal tissue for avoidance, the incidence of fracture for certain subpopulations of adults and children is substantial and suggests that a greater understanding of the underlying clinical factors, dosimetry and biology are needed.

Bone growth-Alterations in bone growth are common considerations in the pediatric age group. This is not a concern in adults. It presents slowly, but can result in dramatic alteration in bone length and volume as well as associated muscle hypoplasia (Fig. 6). Understanding the etiology of these alterations has been a long standing pursuit (42-54). Many models to describe bone growth have been multi-factorial, and include age, bone location and type, volume of bone irradiated, and RT dose (55-57). Alteration in vasculature and chondrocyte populations are suspected as the biologic basis of RT's effect on bone length and bone volume, resulting in facial asymmetry, extremity shortening, clavicular shortening, reduced sitting height, and long bone asymmetry $(53,55,56,58-60)$. Growth of flat bones, including the facial bones, clavicle, and pelvis has been correlated with dosimetric and clinical endpoints. Multiple threshold doses have been considered with the most obvious and significant loses of bone growth occurring in patients receiving higher doses and larger volumes of treatment. Models suggest that a significant volume of flat bone growth may be lost as the integral dose >35 Gy delivered to bone increases (57). Age is a highly significant covariate, and children <5 years of age experienced statistically greater bone loss than that of older children, as anticipated. Though the magnitude of flat bone growth loss is greatest in the youngest children, this study and others note that growth loss is continuous. When examined closely, even older patients and those receiving lower doses of RT will have some reduction in bone growth over time $(55,57,60)$. This continuous effect is also noted for long bones and can be seen by clinically measuring stature compared to normative data, vertebral height across 2 dose groups, or long bone length $(46,55,57,61)$. Though a continuous relationship between bone growth loss, dose, and age may be defined, it is worthwhile to consider thresholds in the context of RT planning to at least provide a goal for normal tissue avoidance. Doses $\geq 15 \mathrm{~Gy}$, particularly those $>30$ Gy, appear to result in the most clinically measurable effects.

Little clinical work has been published that describes the biologic events responsible for changes in bone growth. Changes to the epi??physis including widening of the growth plate and formation of a metaphyseal line are noted on plain radiographs following radiation to the ? $\mathrm{e}$ [iphysis (53). Alterations in bone growth were not uniformly seen with radiation doses $>39$ Gy and subsequent abnormal findings in the ?epiphysis, suggesting that a process of repair may occur in some patients. Normal growth plate biology incorporates endocrine and paracrine signaling of chondrocytes, angiogenesis, and modeling and remodeling of the extracellular matrix. These processes are disrupted by RT, the latter which was originally thought to be a permanent alteration but may be reversible. Animal experiments suggest that chondrocytes exhibit some degree of restoration following single fraction and fractionated radiation (62, 63 ). This restoration of function, as well as evidence that melatonin may provide a protective effect on the ?epiphysis in rats, indicates that better understanding of the biology of the process would not only improve our ability to predict patients and dosimetric features at high risk for growth loss, but also may provide targets for prophylaxis in those patients requiring RT to the bone (64). 


\section{CONCLUSIONS}

Clinical, dosimetric and biologic investigations of RT-related normal tissue effects in adults and children remain an important area of research. Frequently relying on input from our physics and biology colleagues, we incorporate variables and methods to enhance our understanding of these tissue effects. Integration of measurable endpoints, derived from collaborations with pediatric or adult medical oncologists and other sub-specialists, allow us to design clinical trials and research studies to identify treatment effects, their severity and the degree to which they affect our patients. The examples given here, lung and bone, are indeed just examples. Similar discussions could have been presented for other organs. Understanding the skeletal and pulmonary effects of RT in adults and children is important for the care of our patients and design of clinical trials, yet on a more basic level these two tissue systems demonstrate what is good and bad about our approaches to normal tissue research across the age spectrum. To further the progress we have made, age must no longer create a barrier for discussion, but should comprise a variable for study. Meetings, journals, and other forums must accept that pediatrics and adults often should be discussed together, not apart, when normal tissues are concerned. Our progress and our patients will both benefit when we look across the ages and borrow from those that are younger or older.

\section{Acknowledgments}

Supported in part by the American Lebanese Syrian Associated Charities (ALSAC) and the Lance Armstrong Foundation

\section{Reference List}

1. Moreno M, Aristu J, Ramos LI, et al. Predictive factors for radiation-induced pulmonary toxicity after three-dimensional conformal chemoradiation in locally advanced non-small-cell lung cancer. Clin Transl Oncol 2007;9(9):596-602. [PubMed: 17921108]

2. Kocak Z, Evans ES, Zhou SM, et al. Challenges in defining radiation pneumonitis in patients with lung cancer. Int J Radiat Oncol Biol Phys 2005;62(3):635-8. [PubMed: 15936538]

3. Frankovich J, Donaldson SS, Lee Y, et al. High-dose therapy and autologous hematopoietic cell transplantation in children with primary refractory and relapsed Hodgkin's disease: atopy predicts idiopathic diffuse lung injury syndromes. Biol Blood Marrow Transplant 2001;7(1):49-57. [PubMed: 11215699]

4. Kwa SL, Lebesque JV, Theuws JC, et al. Radiation pneumonitis as a function of mean lung dose: an analysis of pooled data of 540 patients. Int J Radiat Oncol Biol Phys 1998;42(1):1-9. [PubMed: 9747813]

5. Koh ES, Sun A, Tran TH, et al. Clinical dose-volume histogram analysis in predicting radiation pneumonitis in Hodgkin's lymphoma. Int J Radiat Oncol Biol Phys 2006;66(1):223-8. [PubMed: 16904523]

6. Krengli M, Sacco M, Loi G, et al. Pulmonary changes after radiotherapy for conservative treatment of breast cancer: a prospective study. Int J Radiat Oncol Biol Phys 2008;70(5):1460-7. [PubMed: 17931797]

7. Graham MV, Purdy JA, Emami B, et al. Clinical dose-volume histogram analysis for pneumonitis after 3D treatment for non-small cell lung cancer (NSCLC). Int J Radiat Oncol Biol Phys 1999;45(2):3239. [PubMed: 10487552]

8. Martel MK, Ten Haken RK, Hazuka MB, et al. Dose-volume histogram and 3-D treatment planning evaluation of patients with pneumonitis. Int J Radiat Oncol Biol Phys 1994;28(3):575-81. [PubMed: 8113100]

9. Hernando ML, Marks LB, Bentel GC, et al. Radiation-induced pulmonary toxicity: a dose-volume histogram analysis in 201 patients with lung cancer. Int J Radiat Oncol Biol Phys 2001;51(3):650-9. [PubMed: 11597805] 
10. Hua C, Hoth K, Kun LE, et al. Radiation Pneumonitis of Pediatric Patients with Sarcoma and Hodgkin's Lymphoma: A DVH Analysis. Int J Radiat Oncol Biol Phys 2008;72:s494. abstr.

11. Hua C, Hoth K, Kun LE, et al. Are dosimetric guildlines of adult lung cancer for preventing radiation pneumonitis applicable to pediatric radiotherapy involving lungs? Med Phys 2008;35(6):2912. abstr.

12. Marks LB. Dosimetric predictors of radiation-induced lung injury. Int J Radiat Oncol Biol Phys 2002;54(2):313-6. [PubMed: 12243802]

13. Marks LB, Bentzen SM, Deasy JO, et al. Radiation dose volume effects in the lung. Int J Radiat Oncol Biol Phys. In press.

14. Schneider RA, Schultze J, Jensen JM, et al. 20 years of experience in static intensity-modulated totalbody irradiation and lung toxicity: Results in 257 consecutive patients. Strahlenther Onkol 2007;183 (10):545-51. [PubMed: 17896085]

15. Kahan Z, Csenki M, Varga Z, et al. The risk of early and late lung sequelae after conformal radiotherapy in breast cancer patients. Int J Radiat Oncol Biol Phys 2007;68(3):673-81. [PubMed: 17350177]

16. Johansson S, Bjermer L, Franzen L, et al. Effects of ongoing smoking on the development of radiationinduced pneumonitis in breast cancer and oesophagus cancer patients. Radiother Oncol 1998;49(1): 41-7. [PubMed: 9886696]

17. Kong FM, Ao X, Wang L, et al. The use of blood biomarkers to predict radiation lung toxicity: a potential strategy to individualize thoracic radiation therapy. Cancer Control 2008;15(2):140-50. [PubMed: 18376381]

18. Zhao L, Sheldon K, Chen M, et al. The predictive role of plasma TGF-beta1 during radiation therapy for radiation-induced lung toxicity deserves further study in patients with non-small cell lung cancer. Lung Cancer 2008;59(2):232-9. [PubMed: 17905467]

19. Hartsell WF, Scott CB, Dundas GS, et al. Can serum markers be used to predict acute and late toxicity in patients with lung cancer?: Analysis of RTOG 91-03. Am J Clin Oncol 2007;30(4):368-76. [PubMed: 17762437]

20. Rube CE, Palm J, Erren M, et al. Cytokine plasma levels: reliable predictors for radiation pneumonitis? PLoS ONE 2008;3(8):e2898. [PubMed: 18682839]

21. Lind PA, Marks LB, Hollis D, et al. Receiver operating characteristic curves to assess predictors of radiation-induced symptomatic lung injury. Int J Radiat Oncol Biol Phys 2002;54(2):340-7. [PubMed: 12243806]

22. Hart JP, McCurdy MR, Ezhil M, et al. Radiation pneumonitis: correlation of toxicity with pulmonary metabolic radiation response. Int J Radiat Oncol Biol Phys 2008;71(4):967-71. [PubMed: 18495373]

23. Yorke ED, Jackson A, Rosenzweig KE, et al. Dose-volume factors contributing to the incidence of radiation pneumonitis in non-small-cell lung cancer patients treated with three-dimensional conformal radiation therapy. Int J Radiat Oncol Biol Phys 2002;54(2):329-39. [PubMed: 12243805]

24. Le Chevalier T, Arriagada R, Quoix E, et al. Radiotherapy alone versus combined chemotherapy and radiotherapy in unresectable non-small cell lung carcinoma. Lung Cancer 1994;10(suppl 1):s239s244. [PubMed: 8087515]

25. Mertens AC, Yasui Y, Liu Y, et al. Pulmonary complications in survivors of childhood and adolescent cancer. A report from the Childhood Cancer Survivor Study. Cancer 2002;95(11):2431-41. [PubMed: 12436452]

26. Oguz A, Tayfun T, Citak EC, et al. Long-term pulmonary function in survivors of childhood Hodgkin disease and non-Hodgkin lymphoma. Pediatr Blood Cancer 2007;49(5):699-703. [PubMed: 17420991]

27. Weiner DJ, Maity A, Carlson CA, et al. Pulmonary function abnormalities in children treated with whole lung irradiation. Pediatr Blood Cancer 2006;46(2):222-7. [PubMed: 15926160]

28. Borst GR, De JK, Belderbos JS, et al. Pulmonary function changes after radiotherapy in non-smallcell lung cancer patients with long-term disease-free survival. Int J Radiat Oncol Biol Phys 2005;62 (3):639-44. [PubMed: 15936539]

29. Theuws JC, Seppenwoolde Y, Kwa SL, et al. Changes in local pulmonary injury up to 48 months after irradiation for lymphoma and breast cancer. Int J Radiat Oncol Biol Phys 2000;47(5):1201-8. [PubMed: 10889373] 
30. Miller KL, Zhou SM, Barrier RC Jr, et al. Long-term changes in pulmonary function tests after definitive radiotherapy for lung cancer. Int J Radiat Oncol Biol Phys 2003;56(3):611-5. [PubMed: 12788165]

31. Ma J, Zhang J, Zhou S, et al. Regional lung density changes after radiation therapy for tumors in and around thorax. Int J Radiat Oncol Biol Phys. 2009 Apr 28; e-publication.

32. Fan M, Marks LB, Hollis D, et al. Can we predict radiation-induced changes in pulmonary function based on the sum of predicted regional dysfunction. J Clin Oncol 2001;19(2):543-50. [PubMed: 11208849]

33. Fan M, Marks LB, Lind $P$, et al. Relating radiation-induced regional lung injury to changes in pulmonary function tests. Int J Radiat Oncol Biol Phys 2001;51(2):311-7. [PubMed: 11567804]

34. Bradley J, Graham MV, Winter K, et al. Toxicity and outcome results of RTOG 9311: a phase I-II dose-escalation study using three-dimensional conformal radiotherapy in patients with inoperable non-small-cell lung carcinoma. Int J Radiat Oncol Biol Phys 2005;61(2):318-28. [PubMed: 15667949]

35. Regaud C. Sur la sensibilite du tissu osseux normal vis-a-vis des rayons X et gamma et sur la mecanisme de l'osteoradionecrose. CR Soc Biol (Paris) 1922;87:629-932.

36. Curi MM, Dib LL. Osteoradionecrosis of the jaws: a retrospective study of the background factors and treatment in 104 cases. J Oral Maxillofac Surg 1997;55(6):540-4. [PubMed: 9191633]

37. Cheon YW, Lee MC, Kim YS, et al. Gluteal artery perforator flap: a viable alternative for sacral radiation ulcer and osteoradionecrosis. J Plast Reconstr Aesthet Surg. 2009 Apr 2; e-publication.

38. Mendenhall WM. Mandibular osteoradionecrosis. J Clin Oncol 2004;22(24):4867-8. [PubMed: 15520050]

39. Reuther T, Schuster T, Mende U, et al. Osteoradionecrosis of the jaws as a side effect of radiotherapy of head and neck tumour patients--a report of a thirty year retrospective review. Int J Oral Maxillofac Surg 2003;32(3):289-95. [PubMed: 12767877]

40. Lee IJ, Koom WS, Lee CG, et al. Risk Factors and Dose-Effect Relationship for Mandibular Osteoradionecrosis in Oral and Oropharyngeal Cancer Patients. Int J Radiat Oncol Biol Phys. 2009 Mar 25; e-publication.

41. Teng MS, Futran ND. Osteoradionecrosis of the mandible. Curr Opin Otolaryngol Head Neck Surg 2005;13(4):217-21. [PubMed: 16012245]

42. Ruggiero SL, Mehrotra B, Rosenberg TJ, et al. Osteonecrosis of the jaws associated with the use of bisphosphonates: a review of 63 cases. J Oral Maxillofac Surg 2004;62(5):527-34. [PubMed: 15122554]

43. Studer G, Studer SP, Zwahlen RA, et al. Osteoradionecrosis of the mandible: minimized risk profile following intensity-modulated radiation therapy (IMRT). Strahlenther Onkol 2006;182(5):283-8. [PubMed: 16673062]

44. Annane D, Depondt J, Aubert P, et al. Hyperbaric oxygen therapy for radionecrosis of the jaw: a randomized, placebo-controlled, double-blind trial from the ORN96 study group. J Clin Oncol 2004;22(24):4893-900. [PubMed: 15520052]

45. Indelicato DJ, Keole SR, Shahlaee AH, et al. Definitive radiotherapy for ewing tumors of extremities and pelvis: long-term disease control, limb function, and treatment toxicity. Int J Radiat Oncol Biol Phys 2008 Nov;72(3):871-7. [PubMed: 18455323]

46. Paulino AC. Late effects of radiotherapy for pediatric extremity sarcomas. Int J Radiat Oncol Biol Phys 2004;60(1):265-74. [PubMed: 15337565]

47. Coletti D, Ord RA. Treatment rationale for pathological fractures of the mandible: a series of 44 fractures. Int J Oral Maxillofac Surg 2008;37(3):215-22. [PubMed: 18023145]

48. Engleman MA, Woloschak G, Small W Jr. Radiation-induced skeletal injury. Cancer Treat Res 2006;128:155-69. [PubMed: 16335017]

49. Lin PP, Schupak KD, Boland PJ, et al. Pathologic femoral fracture after periosteal excision and radiation for the treatment of soft tissue sarcoma. Cancer 1998;82(12):2356-65. [PubMed: 9635528]

50. Helmstedter CS, Goebel M, Zlotecki R, et al. Pathologic fractures after surgery and radiation for soft tissue tumors. Clin Orthop Relat Res 2001;389:165-72. [PubMed: 11501806]

51. Dickie CI, Parent AL, Griffin AM, et al. Bone Fractures Following External Beam Radiotherapy and Limb-Preservation Surgery for Lower Extremity Soft Tissue Sarcoma: Relationship to Irradiated 
Bone Length, Volume, Tumor Location and Dose. Int J Radiat Oncol Biol Phys. 2009 Apr 11; epublication.

52. Probert JC, Parker BR. The effects of radiation therapy on bone growth. Radiology 1975;114(1):15562. [PubMed: 813276]

53. De Smet AA, Kuhns LR, Fayos JV, et al. Effects of radiation therapy on growing long bones. AJR Am J Roentgenol 1976;127(6):935-9. [PubMed: 998830]

54. Littman PS, D'Angio GJ. Growth considerations in the radiation therapy of children with cancer. Annu Rev Med 1979;30:405-15. [PubMed: 400502]

55. Silber JH, Littman PS, Meadows AT. Stature loss following skeletal irradiation for childhood cancer. J Clin Oncol 1990;8(2):304-12. [PubMed: 2299373]

56. Willman KY, Cox RS, Donaldson SS. Radiation induced height impairment in pediatric Hodgkin's Disease. Int J Radiat Oncol Biol Phys 1994;28(1):85-92. [PubMed: 8270462]

57. Krasin MJ, Xiaoping X, Shengjie W, et al. The effects of external beam irradiation on the growth of flat bones in children: Modeling a dose-volume effect. Int J Radiat Oncol Biol Phys 2005;62(5): 1458-62. [PubMed: 16029808]

58. Eifel PJ, Donaldson SS, Thomas PR. Response of growing bone to irradiation: a proposed late effects scoring system. Int J Radiat Oncol Biol Phys 1995;31(5):1301-7. [PubMed: 7713789]

59. Kaste SC, Chen G, Fontanesi J, et al. Orbital development in long-term survivors of retinoblastoma. J Clin Oncol 1997;15(3):1183-9. [PubMed: 9060562]

60. Merchant TE, Nguyen L, Nguyen D, et al. Differential attenuation of clavicle growth after asymmetric mantle radiotherapy. Int J Radiat Oncol Biol Phys 2004;59(2):556-61. [PubMed: 15145176]

61. Hartley KA, Li C, Laningham FH, et al. Vertebral body growth after craniospinal irradiation. Int J Radiat Oncol Biol Phys 2008 Apr 1;70(5):1343-9. [PubMed: 18164830]

62. Horton JA, Margulies BS, Strauss JA, et al. Restoration of growth plate function following radiotherapy is driven by increased proliferative and synthetic activity of expansions of chondrocytic clones. J Orthop Res 2006;24(10):1945-56. [PubMed: 16917904]

63. Damron TA, Horton JA, Pritchard MR, et al. Histomorphometric evidence of growth plate recovery potential after fractionated radiotherapy: an in vivo model. Radiat Res 2008;170(3):284-91. [PubMed: 18763859]

64. Topkan E, Tufan H, Yavuz AA, et al. Comparison of the protective effects of melatonin and amifostine on radiation-induced epiphyseal injury. Int J Radiat Biol 2008;84(10):796-802. [PubMed: 18979313] 


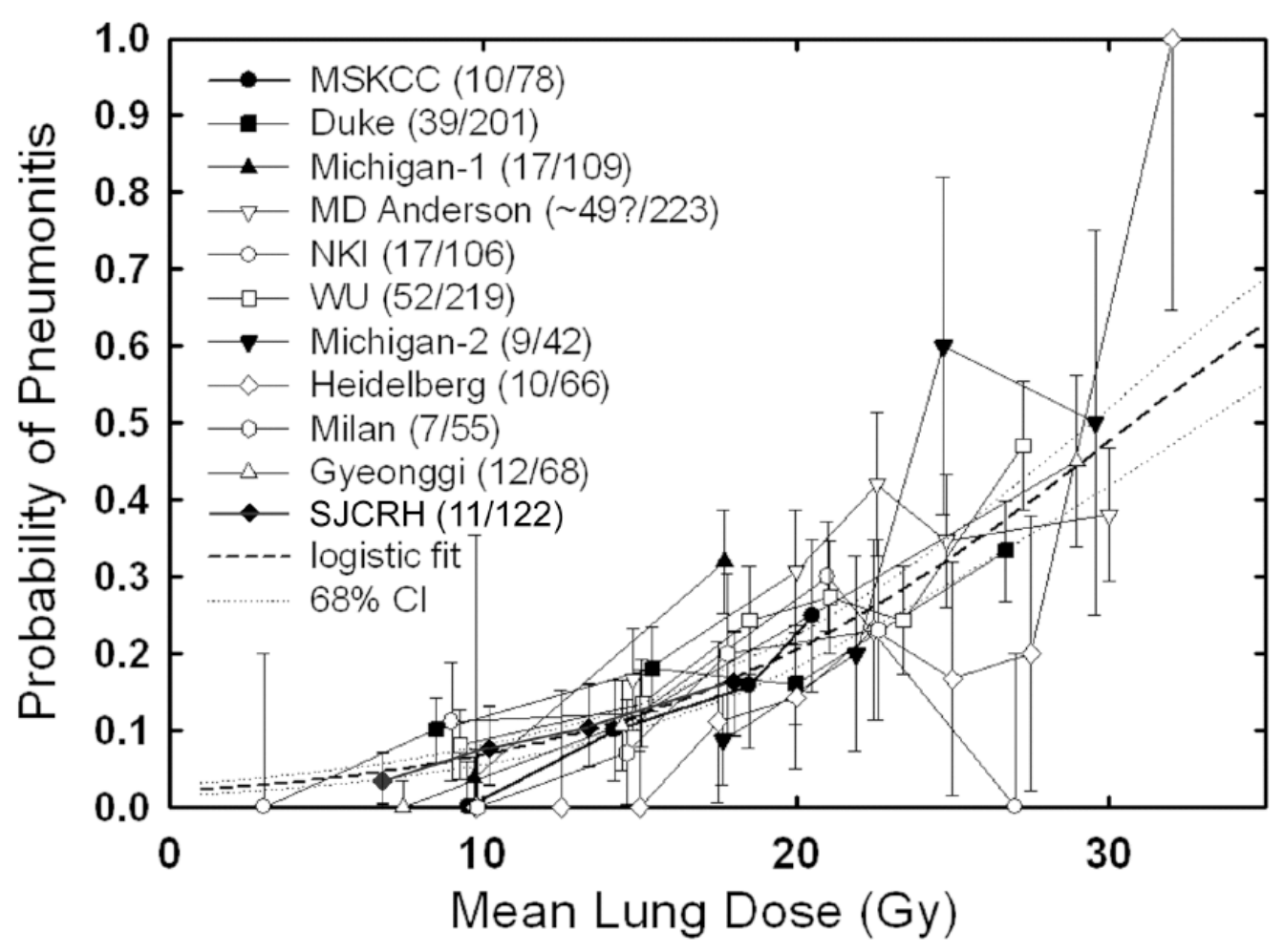

Fig 1.

MLD plotted against pneumonitis risk in adults and children. 


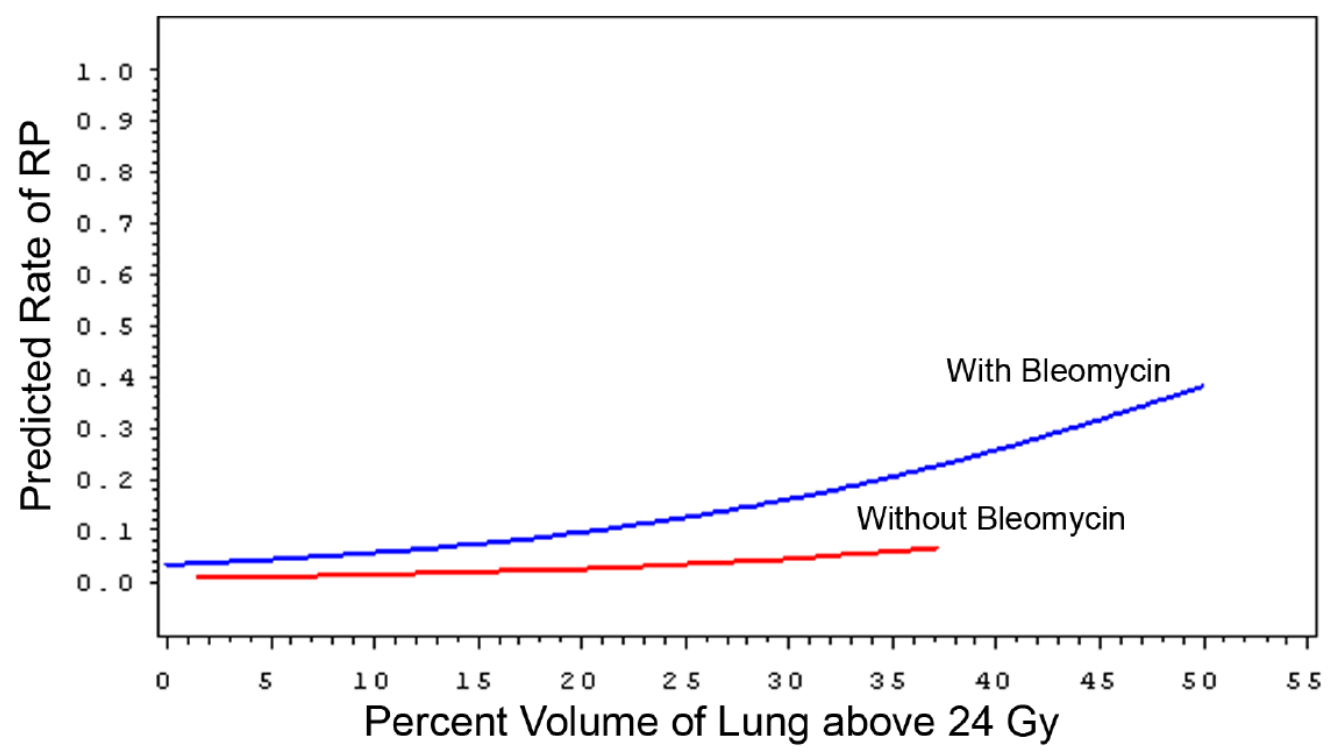

Fig 2.

Probability of symptomatic radiation pneumonitis for 99 patients with Hodgkin's disease receiving radiation with or without bleomycin based on percent volume of total lung irradiated above $24 \mathrm{~Gy}$ 

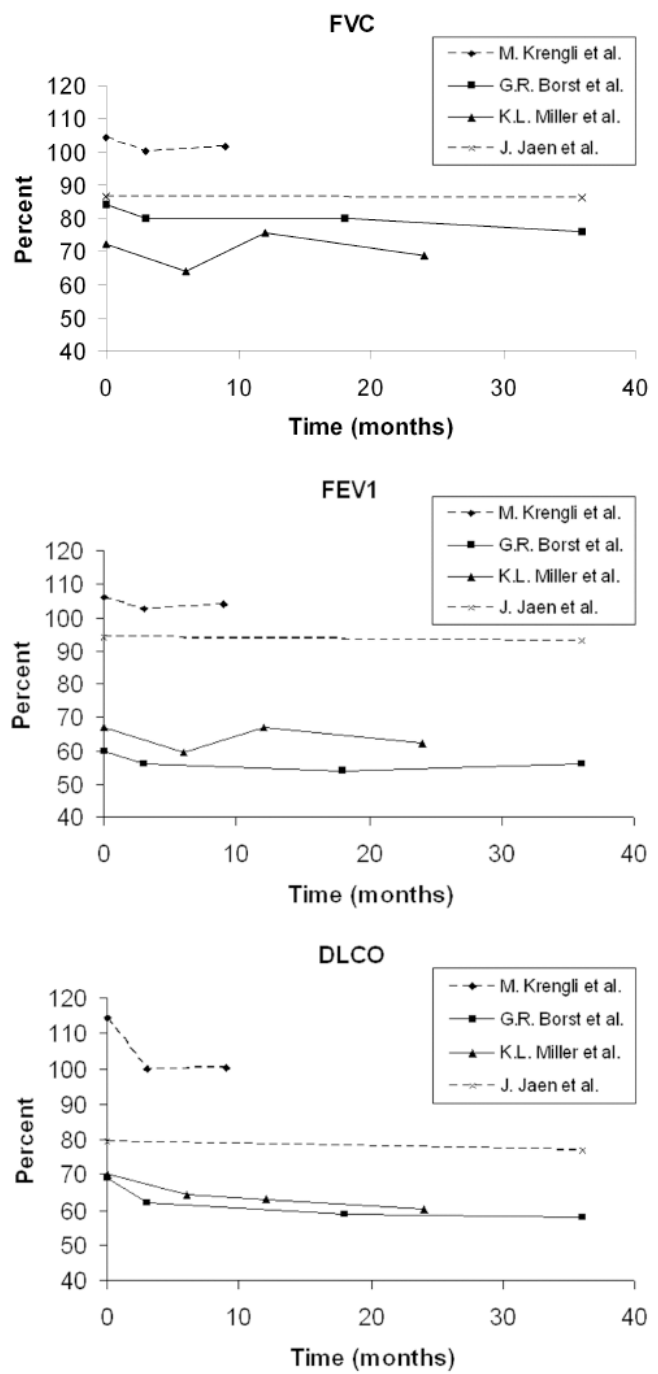

Figure 3.

Trends for pulmonary function studies following radiation therapy to the chest in adult patients. 

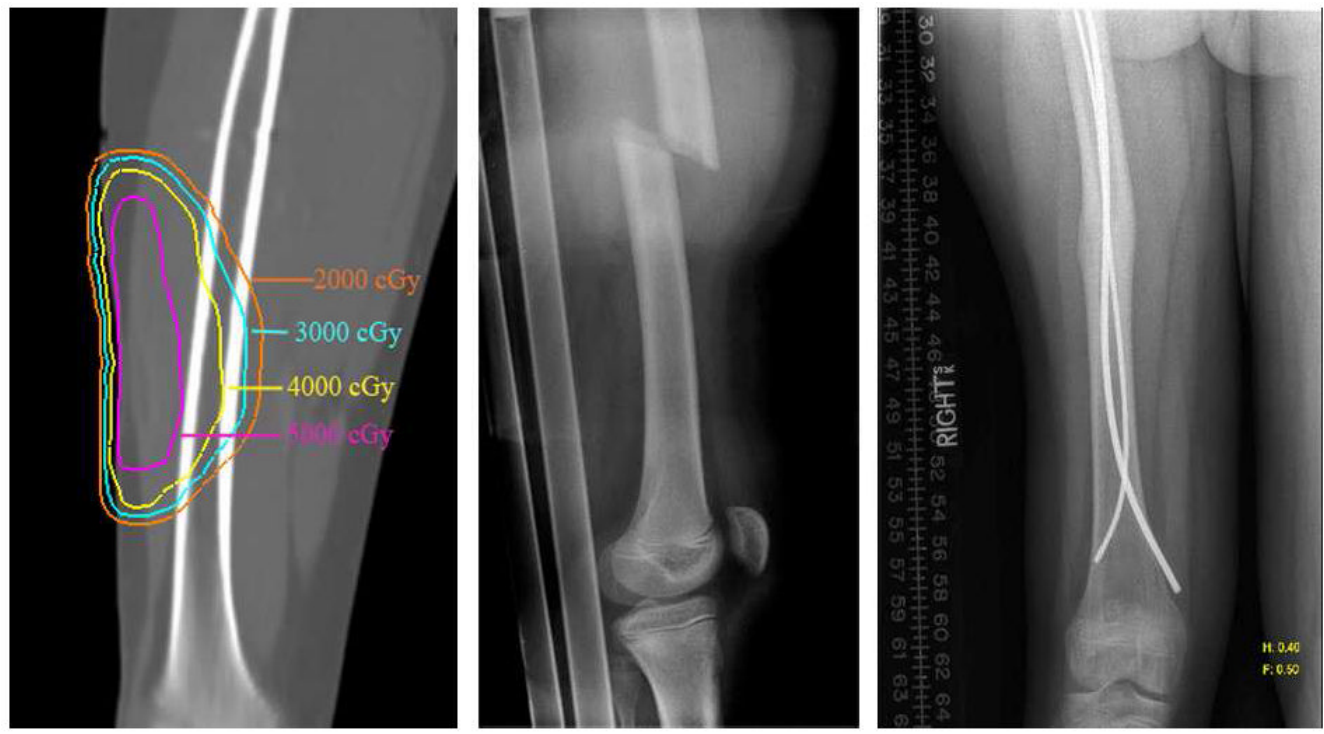

Figure 4.

Dosimetry, fracture and subsequent repair and healing of a femoral fracture following a cartwheel in a child managed with radiation therapy to the thigh for rhabdomyosarcoma. 


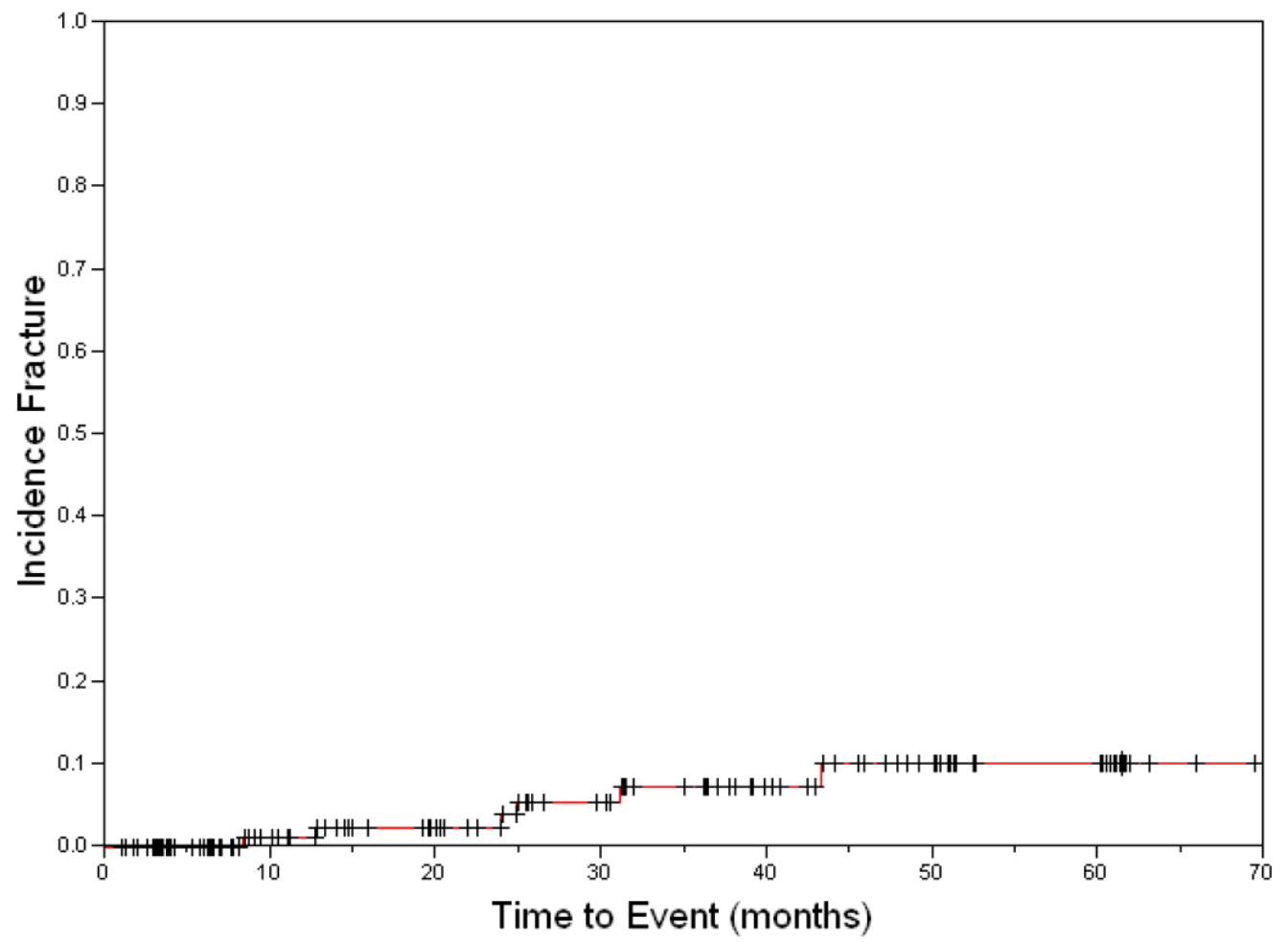

Figure 5.

Cumulative incidence of fractures in a clinical trial of 129 pediatric and young adult patients receiving radiation therapy for soft-tissue and bone sarcomas. 


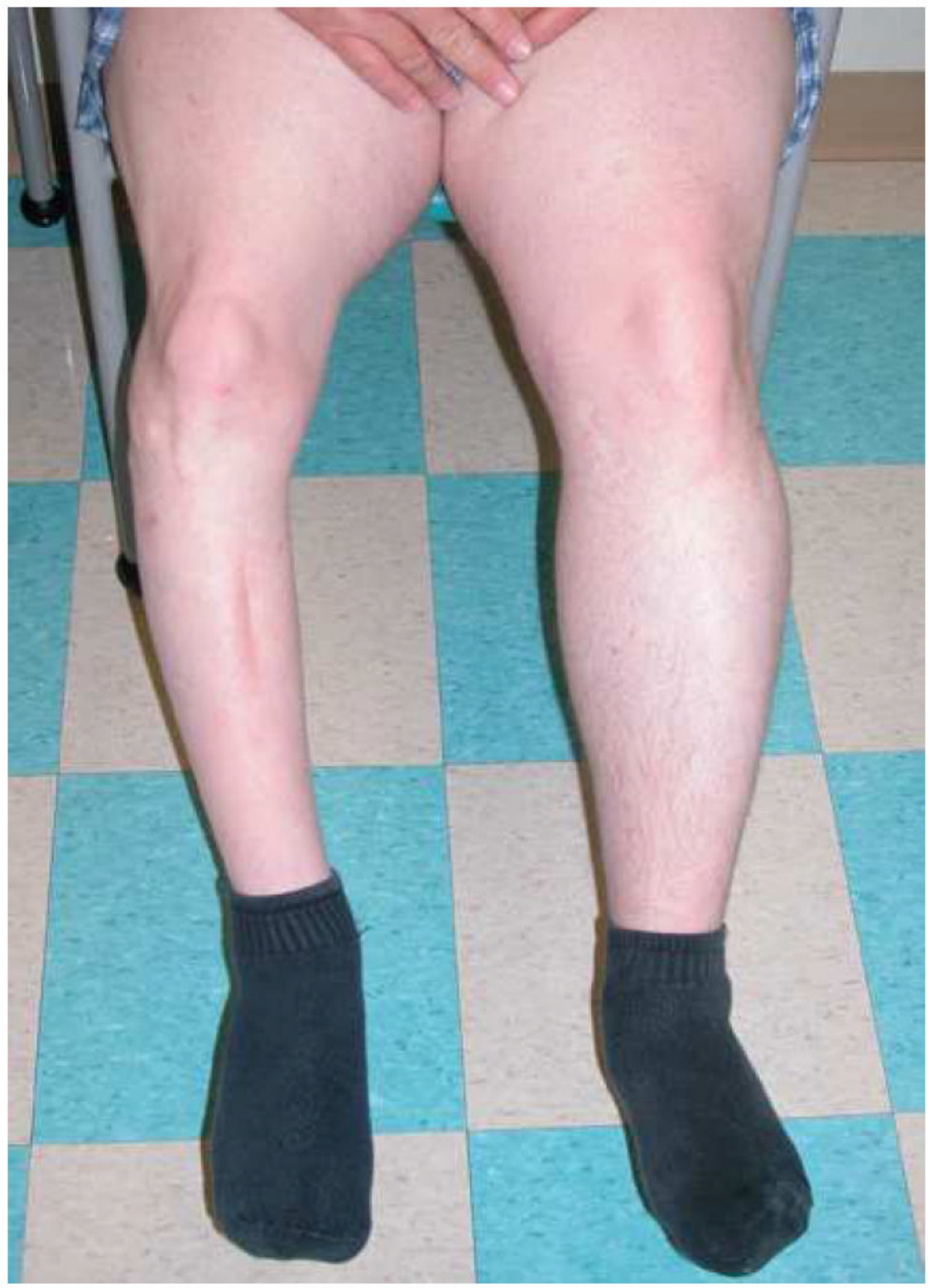

Figure 6.

A long term survivor of whole-bone radiation for Ewing's sarcoma demonstrating limb shortening, volume loss and hypoplasia. 
Table 1

General comparison of late effects between children and adults.

\begin{tabular}{|l|l|l|}
\hline Aspects of late effects & Children & Adults \\
\hline $\begin{array}{l}\text { Incidence of cancer (Population } \\
\text { at Risk) }\end{array}$ & Low & High \\
\hline Classification of late effects & Evolving over time & Binary \\
\hline $\begin{array}{l}\text { Likelihood of some measurable } \\
\text { late effect }\end{array}$ & High ( 75-100\%) & Variable ( 20-50\%) \\
\hline Importance of age at RT & Critical & Limited \\
\hline $\begin{array}{l}\text { Ability to accurately quantify } \\
\text { the risk }\end{array}$ & $\begin{array}{l}\text { Poor, small numbers, limited } \\
\text { statistical power }\end{array}$ & $\begin{array}{l}\text { Good, large numbers, adequate } \\
\text { statistics, limited by follow-up and } \\
\text { competing risks of death }\end{array}$ \\
\hline
\end{tabular}


Table 2

RT-associated lung injury in children and adults.

\begin{tabular}{|l|l|l|}
\hline Aspects of RT-associated lung injury & Children & Adults \\
\hline Common endpoints & $\begin{array}{l}\text { Radiation fibrosis, } \\
\text { alterations in PFTs }\end{array}$ & Radiation pneumonitis \\
\hline Pre-existing lung disease & Uncommon & Very common \\
\hline $\begin{array}{l}\text { Effect of pre-existing lung disease on risk } \\
\text { of RT-associated lung injury }\end{array}$ & Minimal & Moderate \\
\hline Presence of cancer in the lung itself & Rare - adjacent tumors & Common \\
\hline $\begin{array}{l}\text { Diagnostic certainty of lung injury's } \\
\text { relation to RT }\end{array}$ & High & $\begin{array}{l}\text { Moderate - at times very unclear due to } \\
\text { comorbid conditions }\end{array}$ \\
\hline Underlying pathology & $\begin{array}{l}\text { More frequent restrictive } \\
\text { deficits }\end{array}$ & Parenchymal injury limiting perfusion \\
\hline
\end{tabular}


Table 3

RT-associated skeletal injury in children and adults.

\begin{tabular}{|l|l|l|}
\hline Aspects of RT-associated skeletal injury & Children & Adults \\
\hline General concern during RT planning & High & Low \\
\hline Primary issue & Growth & Necrosis, fracture \\
\hline $\begin{array}{l}\text { Effect of pre-existing lung disease on risk of } \\
\text { RT-associated lung injury }\end{array}$ & Minimal & Moderate \\
\hline Dose limit & Low $\sim 30 \mathrm{~Gy}$ & High $\sim 60 \mathrm{~Gy}+$ \\
\hline Bone at risk & Any & $\begin{array}{l}\text { Mandible, weight bearing (i.e. } \\
\text { femur) }\end{array}$ \\
\hline Common clinical scenarios & $\begin{array}{l}\text { Craniospinal irradiation, RT } \\
\text { for sarcomas }\end{array}$ & $\begin{array}{l}\text { Head \& neck cancer, prostate } \\
\text { cancer }\end{array}$ \\
\hline
\end{tabular}

